\title{
ESTUDIOS EPIDEMIOLÓGICOS Y VIROLÓGICOS SOBRE LA POLIOMIELITIS EN VALENCIA (1959-1969) ${ }^{1}$
}

\author{
María José Báguena Cervellera \\ Instituto de Historia de la Medicina y de la Ciencia «López Piñero», Universitat de València-CSIC
}

\section{RESUMEN}

Los estudios sobre el virus de la polio comenzaron en Valencia en 1959 de la mano del microbiólogo Vicente Sanchis-Bayarri Vaillant. Tras su formación en virología en la Universidad de Rochester y en el Instituto Pasteur, puso en marcha un laboratorio de cultivos celulares en la Facultad de Medicina de Valencia, en donde desarrolló una técnica diagnóstica nueva para el virus de la polio. Por otra parte, se llevaron a cabo estudios epidemiológicos antes y después de la campaña de vacunación de 1963, que demostraron la eficacia de la vacuna oral de Sabin y su inocuidad.

PALABRAS CLAVE: Poliomielitis. Poliovirus. Vacunas de la polio. Campañas de vacunación. Epidemiología.

\section{EPIDEMIOLOGICAL AND VIROLOGICAL STUDIES INTO THE POLIOMYELITIS IN VALENCIA (1959-1969)}

\begin{abstract}
Studies into the polio virus began in Valencia in 1959 with the work undertaken by the microbiologist Vicente Sanchis-Bayarri Vaillant. After his education at the Rochester University and at the Pasteur Institute, Sanchis-Bayarri Vaillant established a laboratory of cell cultures at the Faculty of Medicine in Valencia, where he developed a new diagnostic technique for the poliomyelitis virus. In addition, epidemiological studies were carried out both prior to and post the 1963 vaccination campaign, which proved that Sabin's oral vaccine was both effective and safe for use.
\end{abstract}

KEY WORDS: Poliomyelitis. Polio virus. Polio vaccines. Vaccination campaigns. Epidemiology.

1 Este trabajo se enmarca dentro del proyecto «La poliomielitis en la España del siglo XX: repercusiones científicas, profesionales y sociales», financiado por el Ministerio de Educación y Ciencia (HUM2005-07378-C03-01/HIST). 


\section{INTRODUCCIÓN}

Los estudios epidemiológicos y virológicos sobre la polio fueron muy escasos en Valencia antes de 1950. En un trabajo anterior ${ }^{2}$ se daba cuenta de la rápida divulgación de los descubrimientos de Constantin Levaditi, Hydayo Noguchi y Simon Flexner sobre el virus causal de la enfermedad, así como la ausencia de una investigación original valenciana sobre el mismo. En 1913, el pediatra Ramón Gómez Ferrer presentó una comunicación al III Congreso Español de Obstetricia, Ginecología y Pediatría en el que exponía los resultados del estudio que había realizado sobre la distribución geográfica de la polio en la región valenciana ${ }^{3}$. Concluyó que la enfermedad había sido esporádica entre 1893 y 1909 y epidémica entre 1910 y 1912.

Tras el brote epidémico ocurrido en Valencia en 1942, el Jefe Provincial de Sanidad, Juan Durich, publicó un extenso artículo sobre la enfermedad ${ }^{4}$. Como epidemiólogo le interesaba conocer las circunstancias determinantes de la aparición, mantenimiento y transmisión de la misma, por lo que, en su opinión, había que tener presente

«(...) las circunstancias ambientales de lugar y tiempo, e individuales de edad, ocupación, etc., comprobando si unos mismos individuos han sido afectados por infecciones supuestamente distintas y en qué lapso de tiempo; debiendo recurrir en ciertos casos de síndromes cuyo carácter esencial se desconoce, al estudio biológico detenido (investigación del agente causal, pruebas de neutralización de virus, etc.)» ${ }^{5}$.

Tras destacar como características predominantes en la epidemia de 1942 los síntomas meníngeos ${ }^{6}$ y la parálisis facial ${ }^{7}$, se subraya su mayor incidencia en edades tempranas y la importancia del estado endémico preexistente en la provincia de Valencia, con brotes periódicos, como el de 1934 con ochenta y

2 BÁguena CERvellera, M.J. (2004), Saberes y prácticas en torno a la polio en la medicina valenciana (1900-1950). En MARTínEZ PÉREZ, J. et al. (coords.), La medicina ante el nuevo milenio: una perspectiva histórica, Cuenca, Editorial de la Universidad de Castilla-La Mancha, pp. 949-962.

3 Gómez Ferrer, R. (1913), Parálisis infantil. Etiología y patogenia, Actas III Congreso Español de Obstetricia, Ginecología y Pediatría, pp. 210-292.

4 Durich, J. (1946), Contribución al estudio de la poliomielitis, Revista de Sanidad e Higiene Pública, 20 (7), pp. 663-700.

5 DURICH (1946), p. 685.

6 DURICH (1946), p. 664.

7 DURICH (1946), p. 667. 
tres casos declarados o el de 1939 con cincuenta y $\operatorname{cinco}^{8}$. Sin embargo, opina que los datos registrados oficialmente están muy por debajo de la realidad y se apoya en una información aportada por Adolfo López Fernández, director del Sanatorio valenciano de la Malvarrosa, que da cuenta de ochocientos seis enfermos poliomielíticos tratados en este centro entre 1932 y 1945, mientras que los datos oficiales de este periodo registran cuatrocientos cuarenta casos en la provincia de Valencia9.

En 1955, Vicente Sanchis-Bayarri Lahoz, catedrático de Higiene y Microbiología de la Facultad de Medicina de Valencia, publicó un artículo de revisión sobre el valor diagnóstico de los anticuerpos antipoliomielíticos ${ }^{10}$. Partía de los trabajos de Arnold J. Netter y Constantin Levaditi, quienes en 1910 comprobaron su existencia en el suero sanguíneo de individuos que habían padecido la polio ${ }^{11}$. Tras analizar las diferentes técnicas de investigación de estos anticuerpos y su valor práctico, concluyó que la reacción sobre cultivos celulares propuesta por John F. Enders era la que mejor permitía identificar la enfermedad y el tipo serológico que la ocasionaba y esperaba que el método de cultivos en placa que Pierre Lépine acababa de proponer se introdujera pronto en la práctica médica ${ }^{12}$. A lo largo de todo el artículo se muestra convencido de que la existencia de los anticuerpos antipoliomielíticos era un buen indicio de inmunidad adquirida frente a la enfermedad, por lo que su investigación tenía una gran importancia desde el punto de vista epidemiológico y de la medicina preventiva.

8 DURICH (1946), p. 693. En el resto de España, los estudios epidemiológicos sobre la polio demostraban también la mayor incidencia de la enfermedad en niños menores de cinco años. Entre ellos destacan: GonZÁlez RodRíGueZ, P. (1951), Epidemia de poliomielitis en España en 1950, Madrid, Publicaciones «Al servicio del niño español», $\mathrm{M}^{\circ}$ de la Gobernación; GonzÁlez Rodríguez, P. (1953), Aspectos epidemiológico y social de la poliomielitis. La Parálisis infantil en España, Madrid, Dirección General de Sanidad.

9 DURICH (1946), p. 694.

10 SANChIS-BAYARRI LAHOZ, V. (1955), Los anticuerpos anti-poliomielíticos y su valor diagnóstico. Estado actual, Medicina Española, 34 (196), pp. 1-28.

11 Algunos de sus trabajos sobre este tema se publicaron traducidos en la prensa médica valenciana: Netter, A. (1915), Seroterapia de la poliomielitis, Policlínica, 3, pp. 1057-1073; NetTer, A. (1916), Seroterapia de la poliomielitis, Medicina Valenciana, 16, p. 92. Entre 1926 y 1927, Sanchis-Bayarri había sido alumno pensionado de la Junta para la Ampliación de Estudios en el Instituto Pasteur de París, en donde trabajó con Levaditi. A lo largo de 1928 prolongó su estancia como Assistant adscrito al laboratorio de dicho investigador.

12 SANCHIS-BAYARRI LAHOZ (1955), p. 26. 
ESTUDIOS PREVIOS A LA CAMPAÑA DE VACUNACIÓN CONTRA LA POLIOMIELITIS (1959-1962). LA APORTACIÓN DE VICENTE SANCHIS-BAYARRI VAILLANT

La Sociedad Valenciana de Pediatría fue una de las instituciones más activas en la difusión de las novedades que se producían en la investigación sobre la poliomielitis. Sus sesiones eran foros de discusión de los pediatras valencianos, reflejados en su órgano de expresión, el Boletín de la Sociedad Valenciana de Pediatría. En 1959, el pediatra y puericultor del Estado José Boix Barrios exponía en una de estas sesiones los problemas prácticos que planteaba la vacunación contra la polio ${ }^{13}$. Daba cuenta de las vacunas existentes en ese momento, tanto las compuestas por virus inactivados (de Salk, de Lépine), como atenuados (de Sabin, de Koprowski) y los estudios que habían llevado hasta ellas. Dado el estado experimental de las segundas, resumía las recomendaciones para la aplicación de la vacuna Salk y proponía llegar entre todos los miembros de la Sociedad a una pauta uniforme acerca de quiénes debían recibir la vacuna y en qué época, así como solicitar a las autoridades su abastecimiento y generalización ${ }^{14}$.

También en 1959, Vicente Sanchis-Bayarri Vaillant realizaba sus primeras investigaciones sobre la poliomielitis. Era hijo de Sanchis-Bayarri Lahoz y se había licenciado en Medicina en Valencia en 1956. Durante los dos años siguientes fue becario del Departamento de Microbiología de la Facultad de Medicina de la Universidad de Rochester (Estados Unidos), en donde trabajó con Herbert R. Morgan, en el Laboratorio de Investigación Virológica, sobre

13 BoIX BArrios, J. (1959), Vacunación anti-polio. Problemas prácticos, Boletín de la Sociedad Valenciana de Pediatría, 1 (1), pp. 25-31. Ese mismo año, Julián Deluc Talens, Profesor Adjunto de Pediatría de la Facultad de Medicina de Valencia, analizaba en otra de estas sesiones las ideas defendidas en ese momento sobre la clínica del periodo agudo de la poliomielitis (Deluc TALENS, J. (1959), Concepciones actuales sobre la clínica del periodo agudo de la parálisis infantil, Boletín de la Sociedad Valenciana de Pediatría, 1 (1), pp. 3377), mientras que en 1962, Carlos Caballé Lancry, Jefe del Servicio de Rehabilitación de la misma Facultad, valoraba la rehabilitación de la parálisis en estos enfermos (CABALLE LANCRY, C. (1962), Rehabilitación de las parálisis de los músculos abdominales de los poliomielíticos, Boletín de la Sociedad Valenciana de Pediatría, 4 (13), pp. 3-10). Algunos aspectos de la asistencia clínica proporcionada a las víctimas de la polio es esta época han sido analizados en Porras, I. y BALlester, R. (2008), The Incorporation of medical Technology for the Treatment of the acute Stage of Poliomyelitis in Spain (1940-1965), Seventh European Social Science History Conference, Lisboa (26 febrero-1marzo 2008).

14 BOIX BARrIOS (1959), p. 30. 
el virus de las paperas ${ }^{15}$. Ello le permitió familiarizarse en el campo de la virología con la experimentación animal, la inoculación de embriones de pollo y los cultivos celulares. La experiencia adquirida le sirvió para trabajar el año siguiente en cultivos celulares del virus de la polio con Pierre Lépine, jefe del Servicio de Virología del Instituto Pasteur, en París. A su vuelta a Valencia puso en marcha, en la cátedra de Higiene y Microbiología de la Facultad de Medicina, un laboratorio de cultivos celulares en el que prosiguió sus estudios sobre el virus poliomielítico. En él y recién nombrado Médico Interno, desarrolló un medio nuevo para cultivos celulares, el suero tindalizado de caballo ${ }^{16}$. En este medio, mantuvo vivas células HELA y L, cepas celulares que le fueron facilitadas por H.R. Morgan desde su laboratorio de Rochester. Los buenos resultados obtenidos le permitieron afirmar: «Dada la facilidad y sencillez de confección del medio lo estimo muy recomendable para el mantenimiento de estas células, las cuales son muy útiles para el estudio de ciertos virus» ${ }^{17}$. Entre ellos se encontraban las tres cepas del virus de la poliomielitis, en cuya investigación utilizó siempre este medio, como se ve en sus trabajos posteriores.

En 1960, ya como Profesor Adjunto de Higiene y Microbiología, publicó con V. Palop Asensio un artículo sobre el virus poliomielítico tipo II y su aislamiento como método diagnóstico de la enfermedad a partir de un caso visto por el segundo firmante del trabajo en el Hospital de San Juan de Dios de Valencia, del que era director ${ }^{18}$. A los dos años de haber padecido la enfermedad, el niño objeto del estudio seguía eliminando el virus, algo excepcional que, para los autores, debía de tenerse en cuenta a efectos epidemiológicos. Al mismo tiempo se comprobó la presencia en sangre de anticuerpos específicos para el virus tipo II $^{19}$. En esta investigación se utilizaron virus

15 Fue el primer becario español que trabajó en este Laboratorio. Los datos biográficos de Vicente Sanchis-Bayarri Vaillant se han obtenido de su expediente personal: Expediente PDI 97/I, Archivo Universitario, Universitat de València y en SANCHIS-BAYARRI VAILlANT, V. (1988), Contribución al diagnóstico de laboratorio de las infecciones por virus, Discurso de recepción en la Real Academia de Medicina de Valencia; Discurso de contestación de Vicente Sanchis-Bayarri Lahoz, Valencia, Real Academia de Medicina de Valencia, pp. 9-10; pp. 55-59.

16 SANChIS-BAYARRI VAILlANT, V. (1959), Cultivos celulares con suero tindalizado de caballo, Medicamenta, 32, pp. 208-211.

17 SANCHIS-BAYARRI VAILLANT (1959), p. 211.

18 SAnchis-Bayarri Vaillant, V., PAlop Asensio, V. (1960), Eliminación prolongada por heces de virus poliomielítico tipo II (Lansing) en un convaleciente, Medicina Española, 43, pp. 97-103.

19 Sanchis-Bayarri Vaillant, Palop Asensio (1960), p. 103. 
poliomielíticos facilitados por el Servicio de Virus del Instituto Pasteur y se empleó como medio de cultivo el suero tindalizado de caballo desarrollado por Sanchis-Bayarri, muy parecido al suero de feto de buey ultrafiltrado allí utilizado por Lépine ${ }^{20}$, con quien Sanchis-Bayarri mantuvo su relación profesional, repitiendo la estancia en su laboratorio en 1969.

Su interés por las reacciones de seroneutralización en cultivos celulares para detectar la presencia de anticuerpos y traducir de esta forma la respuesta del organismo a una infección poliomielítica le llevó a estudiar la inmunización espontánea contra la enfermedad en Valencia. Su principal objetivo era determinar la edad en la cual el cincuenta por ciento de los niños menores de diez años adquirían los anticuerpos para los tres tipos de virus poliomielíticos, en línea con los estudios que M. Pavlatou en Grecia ${ }^{21}$ y R. Martin en Fran$\mathrm{cia}^{22}$ acababan de publicar. En opinión del autor, era éste un dato indispensable para la vigilancia sanitaria de una población, ya que la vacunación en masa es imprescindible cuando la inmunidad global cae por debajo de ese nivel. En Valencia, la edad a la cual el noventa por ciento de los niños estaba protegido contra la polio era los cinco años. Este trabajo fue objeto de una nota previa en las revistas Medicina Española ${ }^{23}$ y el Boletín de la Sociedad Valenciana de Pediatría ${ }^{24}$ y de un artículo, publicado al año siguiente, en los Annales de l'Institut Pasteur ${ }^{25}$.

Con motivo de la celebración en Copenhague de la V Conferencia sobre Poliomielitis en julio de 1960, Sanchis-Bayarri fue invitado por el Comité Organizador a asistir a la misma, siendo el único valenciano entre los nueve españoles presentes. A su vuelta publicó una crónica detallada de todas las sesiones, dedicadas a aspectos generales de la virología y a las vacunas tipo Salk y Sabin ${ }^{26}$.

20 Sanchis-Bayarri Vaillant, Palop Asensio (1960), p. 100.

21 Pavlatou, M. (1958), Étude de l'immunité contre la poliomyélite dans la population de Grèce, Annales de l'Institut Pasteur, 4, pp. 394-403.

22 Martin, R., Roger, F., Damas, S.P., Roger, A. (1959), Deux ans et demi de vaccination antipoliomyélitique (Vaccine Lépine) a l'Hôpital de l'Institut Pasteur, Annales de l'Institut Pasteur, 97, pp. 848-854.

23 SANChIS-BAYARRI VAILlant, V. (1960), Estudio de la inmunización espontánea contra la poliomielitis en Valencia, Medicina Española, 44, pp. 329-330.

24 SANCHIS-BAYARRI VAILLANT, V. (1960), Estudios sobre la inmunización espontánea contra la poliomielitis en Valencia, Boletín de la Sociedad Española de Pediatría, 2(7), pp. 262-263.

25 SANChis-Bayarri Vaillant, V. (1961), Étude de l'immunisation spontanée contre la poliomyélite à Valence (Espagne), Annales de l'Institut Pasteur, 100, pp. 531-538.

26 SAnchis-Bayarri Vaillant, V. (1960), V Conferencia sobre Poliomielitis, Medicina Española, 44, pp. 338-345. 
La rápida utilización de las nuevas técnicas que se incorporaban al diagnóstico de laboratorio es frecuente en los trabajos de este microbiólogo, como por ejemplo el análisis virológico del líquido cefalorraquídeo. Para la mayoría de los autores de la época, el mencionado análisis era constantemente negativo. Sanchis-Bayarri aportó un caso positivo ${ }^{27}$ y concluyó que probablemente el virus se inactivaba con rapidez en el líquido cefalorraquídeo, lo que explicaría el fracaso en conseguir su aislamiento incluso por parte de investigadores muy cualificados, así como la utilización de medios de cultivo inadecuados. Aboga por una siembra inmediata del líquido cefalorraquídeo en el cultivo celular y un medio de cultivo con una elevada proporción de suero, como el tindalizado de caballo ya utilizado por él en trabajos anteriores como se ha comentado.

Sanchis-Bayarri abordó también el problema diagnóstico de las parálisis infantiles producidas por virus diferentes a los poliovirus. Presentó un caso propio de un niño diagnosticado de parálisis infantil en el que se aisló un adenovirus tipo $\mathrm{I}^{28}$. La identificación de este virus fue confirmada, tras la remisión de una muestra, por el Laboratorio de Referencia para Virus del Laboratorio Central de Salud Pública de Londres, en el que el autor había realizado una breve estancia para trabajar con cultivos celulares bajo la dirección de M.T. Parker.

La obtención de una beca «Juan March» de ayuda a la investigación en Ciencias Médicas en 1961 le permitió estudiar la frecuencia y tipos de poliovirus en niños de la región valenciana ${ }^{29}$. Para ello recogió muestras de heces de doscientos cuarenta y un niños con síndrome clínico de poliomielitis o en posible contacto con enfermos de esta naturaleza, procedentes de las consultas de Pediatría de la Facultad de Medicina y del Hospital Provincial, de los Asilos del Carmen (niñas) y de San Juan de Dios (niños), de algunas residencias del Seguro Obligatorio de Enfermedad y de su laboratorio privado. El poliovirus aislado con mayor frecuencia fue el tipo I (en el setenta por ciento de los casos) y no se aisló ningún poliovirus en niños sin manifestaciones clínicas del proceso. En algo menos de la mitad de los casos con poliomielitis clínica se aislaron enterovirus no poliomielíticos y el autor afirmaba que de-

27 SANChis-BAyARri VAillant, V. (1961), El análisis del líquido cefalorraquídeo en el diagnóstico de la poliomielitis, Revista Clínica Española, 82 (1), pp. 21-24.

28 SANChis-BAyARri VAiLlant, V. (1962), Adenovirus tipo I aislado en un caso de parálisis infantil, Medicina Española, 25 (277), pp. 281-287.

29 SANChIS-BAyARri VAILlant, V. (1962), Aislamiento e identificación de «poliovirus» en heces, Revista Clínica Española, 85 (3), pp. 167-173. 
berían identificarse ya que cree que algunos de ellos serían adenovirus ${ }^{30}$, tal y como había demostrado en el caso publicado con anterioridad.

La importancia que las enfermedades víricas tenían para los pediatras llevó a Sanchis-Bayarri a exponer ante la Sociedad Valenciana de Pediatría los métodos diagnósticos de laboratorio existentes en la época y su experiencia personal con los mismos ${ }^{31}$. El artículo que recoge su intervención consta de una primera parte muy técnica en la que describe los métodos de aislamiento del virus, especialmente mediante cultivos en tejidos, al ser «parásitos intracelulares obligados [y] por el efecto que producen en las células que se multiplican $\rangle^{32}$. El cultivo en tejidos era un método bien conocido por el autor desde 1959, como se ha visto y de aquellos virus que causan necrosis celular describe los enterovirus, entre los que se encuentran los virus poliomielíticos, los Coxsackie y los ECHO. Refiere a continuación los métodos de diagnóstico serológico, que demuestran una reacción inmunitaria de naturaleza específica relacionada con la enfermedad y destaca nuevamente las empleadas personalmente por él en poliomielíticos ${ }^{33}$.

La segunda parte de este artículo muestra los resultados obtenidos por el autor, parcialmente publicados en los trabajos anteriores, en un estudio sobre el aislamiento de enterovirus con la técnica de cultivos en tejidos en los años 1959, 1960 y 1961 en Valencia ${ }^{34}$. Se realizaron cuatrocientos cuatro exámenes, tanto en niños sanos como enfermos, diagnosticados o no de poliomielitis y la investigación se llevó a cabo en el Laboratorio de Virología puesto en marcha por el autor en la Cátedra de Higiene y Microbiología de Valencia. Los hallazgos más novedosos fueron la relativa frecuencia de enterovirus en

30 SANChis-BAYARRI VAILlANT (1962), p. 172. En la misma línea se encontraba trabajando por aquel entonces Florencio Pérez Gallardo (1917-2006), jefe de la Sección de Virología y Epidemiología de la Escuela Nacional de Sanidad en Madrid y el mayor experto español en epidemiología de la polio: PÉREz Gallardo, F. (1962), Epidemiología de la poliomielitis en España. Aislamiento de los virus poliomielíticos y otros enterovirus, Revista de Sanidad e Higiene Pública, 36, pp. 605-635.

31 SAnChis-Bayarri Vaillant, V. (1962), Métodos de laboratorio aplicables al diagnóstico de las viriasis infantiles, Boletín de la Sociedad Valenciana de Pediatría, 4 (13), pp. 79-93.

32 SANCHIS-BAYARRI VAILLANT (1962), p. 86.

33 SANChis-BAyARri VAillant (1962), pp. 86-90. También Pérez Gallardo trabajó en el diagnóstico serológico de la poliomielitis: PÉREZ GALLARDO, F. (1962), Epidemiología de la poliomielitis en España. Encuesta serológica para la determinación de los anticuerpos antipoliomielíticos en la población española, Revista de Sanidad e Higiene Pública, 36, pp. 501-518.

34 Utiliza la muestra ya empleada en la investigación financiada con la beca «Juan March» concedida en 1961. 
niños aparentemente sanos, la presencia de enterovirus no poliomielíticos en niños con diagnóstico clínico de poliomielitis y la existencia de los tres tipos de virus poliomielíticos, con predominio del tipo I, al igual que en el resto del mundo. En los niños sanos no se aisló ningún poliovirus, por lo que el autor no suscribe la hipótesis de la existencia de portadores sanos de este virus ${ }^{35}$.

Estos resultados se utilizaron también para la elaboración de otro artículo aparecido en $1963^{36}$ que profundizaba en la técnica de aislamiento de los virus mediante cultivos celulares. En palabras de Sanchis-Bayarri: «Esta técnica confirma u orienta adecuadamente las investigaciones serológicas, puesto que el aislamiento de los virus afirma la posible existencia de determinado proceso» ${ }^{37}$. En ese momento, las investigaciones serológicas para la mayoría de los enterovirus (exceptuando los poliovirus) eran complejas debido a la existencia de gran número de tipos antigénicos, por lo que «en estos casos resulta más práctico el recurrir como medio de identificación al aislamiento de virus que nos dará, por los tipos celulares que afecta, orientación hacia qué tipos determinados deben dirigirse las investigaciones serológicas ${ }^{38}$. La importancia epidemiológica de este estudio, subraya nuevamente su autor, radica en que los enterovirus pueden producir acciones similares en el hombre y ciertos virus del grupo Coxsackie y ECHO son capaces de producir parálisis, al igual que los poliovirus ${ }^{39}$. A modo de conclusión, Sanchis-Bayarri indica: «El haber encontrado enterovirus con notable frecuencia, plantea el problema de que bastantes síndromes poliomielíticos puedan ser ocasionados por enterovirus no poliomielíticos» ${ }^{40}$.

ESTUDIOS EPIDEMIOLÓGICOS Y CAMPAÑA DE VACUNACIÓN CONTRA LA POLIO (1963-1969)

Las investigaciones sobre las técnicas diagnósticas del virus de la polio dieron paso a los estudios epidemiológicos de esta enfermedad, centrados en

35 SANCHIS-BAyARri VAILLANT (1962), p. 92.

36 SANChis-BAyARri VAillant, V. (1963), Estudio en cultivo de tejidos de los virus entéricos aislados en Valencia durante los años 1959, 1960 y 1961, Medicina Clínica, 41 (1), pp. 40-43.

$\begin{array}{ll}37 & \text { SANCHIS-BAYARRI VAILLANT (1963), p. } 40 . \\ 38 & \text { SANCHIS-BAYARRI VAILLANT (1963), p. } 40 . \\ 39 & \text { SANCHIS-BAYARRI VAILLANT (1963), p. } 40 . \\ 40 & \text { SANCHIS-BAYARRI VAILLANT (1963), p. } 43 .\end{array}$ 
valorar los resultados alcanzados con la campaña de vacunación llevada a cabo entre 1963 y 1964.

J. Alcamí, encargado de uno de los centros de vacunación del Instituto Nacional de Previsión de Valencia, expuso su experiencia durante la campaña con vacuna Salk en una sesión de la Sociedad Valenciana de Pediatría ${ }^{41}$. Su principal objetivo era asegurar la inocuidad de la vacuna, tras recoger las reacciones aparecidas en los casi tres mil niños inoculados. Alrededor del cuatro por ciento sufrieron algunos efectos secundarios, todos benignos excepto en dos niños que padecieron alteraciones nerviosas. Estos resultados llevaron al autor a afirmar que la vacuna antipoliomielítica era inofensiva, como siempre se había dicho, incluso aplicada en los primeros meses de vida, pero que debía someterse a observación al niño antes y después de recibir la vacuna. Añadía la conveniencia de realizar un control serológico de su inmunidad unos meses después de ser vacunado y de ampliar la campaña de vacunación en masa al resto de vacunas, como las de la viruela, tuberculosis y la administrada conjuntamente para la difteria, tétanos y tos ferina ${ }^{42}$.

El mismo número del Boletín de la Sociedad Valenciana de Pediatría que daba cuenta de la intervención anterior recogía la sesión informativa que Justiniano Pérez Pardo, Jefe Provincial de Sanidad de Valencia, llevó a cabo en la sede de la Sociedad para informar del inicio, cuatro días después, de la campaña de vacunación con el método Sabin ${ }^{43}$. La justificaba por el aumento alarmante de la poliomielitis desde hacía tres años, a pesar de la reciente campaña con vacuna Salk, a todas luces insuficiente, pues el noventa y nueve por ciento de los casos se dieron en niños no vacunados. El no haber utilizado en su lugar la vacuna de Sabin, ya desarrollada y comprobada en trescientos cincuenta millones de inoculaciones, lo explica el autor por el hecho de estar constituida por virus atenuados y por el miedo de la población al aumento de su virulencia:

41 Alcami García, J. (1963), Vacunación antipoliomielítica en la primera infancia, Boletín de la Sociedad Valenciana de Pediatría, 5 (20), pp. 447-449.

42 AlCAMi García (1963), p. 449.

43 PÉREZ PARDO, J. (1963), Información de la campaña de vacunación antipoliomielítica por vía oral, Boletín de la Sociedad Valenciana de Pediatría, 5 (20), pp. 481-488. La organización nacional de los servicios sanitarios para llevar a cabo la campaña de vacunación contra la polio ha sido estudiada por BAllester, R., BÁGuena, M.J., Porras, M.I. (2007), Spanish Health Services and Polio Epidemics (1940-1980), Conference of the University of Exeter and University of Wales Swansea: Children, Disability and Community Care from 1850 to the present day, Society for the Social History of Medicine, Swansea University and Exeter University (24-25 octubre 2007). 
«Por temor a que los inevitables casos de polio que coincidirían con la campaña de vacunación fueran achacados a una exaltación del virus vacunal, sin poder demostrar lo contrario por carecer de un laboratorio adecuado, desprestigiándose la vacuna, es por lo que el mismo Sabin, así como las autoridades sanitarias, no se atrevieron a implantarla en España. Hoy ya contamos con un servicio de virología en Madrid capaz de discriminar acerca del virus productor de una parálisis» ${ }^{44}$.

Se refería a la Sección de Virología y Epidemiología de la Escuela Nacional de Sanidad, dirigida por Pérez Gallardo ${ }^{45}$. Respaldadas por los comités de expertos de la Organización Mundial de la Salud ${ }^{46}$, las autoridades sanitarias ponían en marcha una campaña con una vacuna segura, eficaz y que producía una inmunidad de por vida ${ }^{47}$. Anunciaba el autor que la vacunación se haría en dos fases separadas por dos meses y sería centralizada por la Jefatura de Sanidad. Tras la intervención de Pérez Pardo, los pediatras asistentes se interesaron por numerosas cuestiones, relativas sobre todo a las contraindicaciones de la vacuna y a la suspensión de la vacuna Salk. Ante el carácter no obligatorio de la campaña, se hacía alusión a la responsabilidad de las madres y al bien común:

«La obligación podemos decir que es moral para todas las madres (...) Ustedes [los médicos] que serán consultados frecuentemente durante esta campaña, la ayu-

44 PÉReZ PARdo (1963), p. 483.

45 Estas nuevas condiciones hicieron que en febrero de 1963 se invitara al propio Albert Sabin a Madrid para que impartiera una conferencia y respaldara la campaña: SABIN, A. (1963), Erradicación de la Poliomielitis: estado actual y perspectivas futuras. Conferencia dada en Madrid en el Consejo Superior de Investigaciones Cientificas, Madrid, CSIC. Con la misma intención fue invitado al mes siguiente Pierre Lépine, quien pronunció un discurso en la Real Academia de Medicina defendiendo la vacunación antipoliomielítica: LEPINE, P. (1963), Vacunaciones y vacunas contra la poliomielitis, Anales de la Real Academia de Medicina, pp. 353-385.

46 Entre 1954 y 1960 la OMS había publicado tres informes monográficos, fruto de las reuniones de trabajo de los Comités de Expertos: OMS (1954), Comité d'experts de la poliomyélite: premier rapport, Rapports techniques, 81, Ginebra, OMS; OMS (1958), Comité de expertos en poliomielitis: segundo informe, Informe técnico, 145, Ginebra, OMS; OMS (1960), Comité de expertos en poliomielitis: tercer informe, Informe técnico, 203, Ginebra, OMS.

47 Las autoridades sanitarias españolas buscaban el respaldo de organismos internacionales como la OMS para legitimar sus actuaciones. Véase, BALLESTER, R., PORRAS, I. (2007), Child protection as a political resource: the influence of international agency recommendations on health campaigns against poliomyelitis in Spain (1940-1975), In the name of Child. The social and cultural History of Children and Youth. Society of the History of Children and Youth 2007 Conference, Linköping (27-30 junio 2007). 
da que pueden hacer es alentar a las madres para que vacunen a sus hijos en bien de todos, de Valencia y de España» ${ }^{48}$.

En 1964, la Sociedad Valenciana de Pediatría volvió a ser escenario de una nueva conferencia sobre la polio a cargo de Vicente Miñana ${ }^{49}$. Comenzó su intervención con una puesta al día de los conocimientos sobre el virus poliomielítico y el mecanismo de transmisión y producción de la enfermedad. Dedicó la parte central de la conferencia a comentar algunos aspectos epidemiológicos de la polio en Valencia en 1963, antes por tanto de completarse la campaña de vacunación tipo Sabin. Los casos encontrados, ciento once, quintuplicaron los de 1959, con un predominio en el medio rural ${ }^{50}$, en el sexo masculino y a los dos años de edad. Tras aludir a las principales características de las dos vacunas disponibles, se muestra partidario de la vacuna Sabin, a pesar de la eficacia comprobada de la vacuna Salk, por su facilidad de administración, por impedir la multiplicación del virus en el intestino, por su inmunidad duradera y por detener la progresión en caso de epidemia. Hace referencia a la vacunación de ciento noventa mil niños en Valencia en la campaña recién concluida y espera que los logros conseguidos sean tan buenos como los obtenidos en otros países:

«Esperamos que los resultados tan alentadores y efectivos de otros países sean los mismos en nuestra patria y región y consigamos eliminar esta terrible enfermedad, que tantos caracteres de dramatismo representa para el individuo, la familia y la sociedad» $»^{51}$.

En 1966, los pediatras E. Borrajo, J. Colomer y F. Martínez, pertenecientes a la Cátedra y Escuela Profesional de Pediatría y Puericultura de la Facultad de Medicina, dirigida por Tomás Sala, publicaron un estudio sobre la epidemiología de la poliomielitis en Valencia entre 1961 y 1965². Los datos del

\footnotetext{
48 PÉREZ PARDo (1963), p. 488.

49 Miñana Serena, V. (1964), Aspectos de la poliomielitis en Valencia, Boletín de la Sociedad Valenciana de Pediatría, 6 (21), pp. 63-69.

50 Los factores determinantes de la diferente aparición de la polio en el medio rural y en el medio urbano durante el periodo estudiado han sido analizados en: PORRAS, M.I., BÁGUENA, M.J., BALlESTER, R. (2007), Health, Development and the rural Environment: the Case of Poliomyelitis in Spain (1940-1975), European Association for the History of Medicine and Health Conference: Environment, Health and History, London (12-15 septiembre 2007).

51 MiÑANA SERENA (1964), p. 69.

52 Borrajo, E., Colomer, J., Martínez Huquet, F. (1966), Epidemiología de la poliomielitis en la región valenciana en los últimos cinco años, Boletín de la Sociedad Castellano-Astur-Leonesa de Pediatría, 7 (26-27), pp. 241-249.
} 
primer trienio sirvieron a los autores para dar a conocer la situación anterior a la campaña de vacunación y compararla con los datos de 1964 y 1965, tras la inoculación masiva con vacuna tipo Sabin. Se recogieron los ciento sesenta y cinco casos de enfermos poliomielíticos vistos en el Servicio de Pediatría del Hospital Clínico de Valencia, que aglutinaba a la mayor parte de los casos de la provincia y se completaron con las noventa y tres fichas epidemiológicas aportadas por el Servicio de Epidemiología de la Jefatura Provincial de Sanidad, lo que hacía un total de doscientos noventa y ocho niños. Se obtuvieron cifras muy semejantes a estudios anteriores, con una morbilidad media de seis casos por cada cien mil habitantes, un notable incremento de la enfermedad en 1963, un ligero predominio en el medio rural y una mortalidad del 0,4 por cada cien mil habitantes. La distribución de la poliomielitis por edades obtuvo resultados similares a los alcanzados por Pérez Gallardo para la media nacional, con casi la mitad de los casos agrupados alrededor del año de edad. Se encontró un ligero predominio en el sexo masculino y una mayor frecuencia en los meses de verano. El virus tipo I produjo el número de casos más elevado, por encima de los tipos II y III. La identificación de la cepa causal la llevó a cabo Vicente Sanchis-Bayarri Vaillant en el Laboratorio de Virología de la cátedra de Microbiología de Valencia ${ }^{53}$.

La procedencia de los casos estudiados habidos después de la campaña de vacunación fue la misma. De los tres niños vistos en el Servicio de Pediatría, dos de ellos enfermaron con anterioridad a la campaña y en el tercero, que había recibido la vacuna tipo Salk, no se aislaron poliovirus. De la Jefatura Provincial de Sanidad se recibieron datos de cinco niños, cuatro de los cuales presentaron la enfermedad cuando la vacunación aún no se había completado y el último fue diagnosticado por los autores de encefalitis y no de poliomielitis. Ante estas cifras, no dudan en calificar de «magníficos» los resultados alcanzados en Valencia por la campaña nacional de vacunación con virus atenuados ${ }^{54}$.

En 1969 se publicaron los resultados de un extenso estudio epidemiológico y virológico sobre la poliomielitis en España en los cinco años transcurridos desde el comienzo de la vacunación antipoliomielítica por vía oral y que contó con una participación del noventa y cinco por ciento de la población española comprendida entre los dos meses y los siete años ${ }^{55}$. Tras ella, la Direc-

53 Borrajo, COlOMER, Martínez Huquet (1966), p. 247.

54 Borrajo, Colomer, Martínez HuQuet (1966), p. 241.

55 Valenciano, L., MezQuita, M., Pérez Gallardo, F., Gabriel y Galán, J. (1969), Estudio epidemiológico y virológico de la poliomielitis en España durante el quinquenio 1964-1968, Revista de Sanidad e Higiene Pública, 43 (7-8), pp. 517-564. 
ción General de Sanidad organizó campañas anuales para vacunar a los niños menores de un año. El empleo de la vacuna oral hizo descender la cifra de casos de poliomielitis de dos mil anuales antes de la campaña a setenta en 1965. No obstante, en los tres años siguientes la cifra aumentó ligeramente, siendo la mayoría de los casos niños menores de dos años sin vacunar o vacunados con una sola dosis. El virus poliomielítico tipo I era el que se detectaba con mayor frecuencia, igual que en años anteriores. El estudio epidemiológico se realizó a partir de los casos sospechosos que cada Jefatura Provincial de Sanidad comunicaba a la Sección de Epidemiología de la Dirección General de Sanidad. Se enviaban muestras de heces, líquido cefalorraquídeo y sangre al Centro Nacional de Virología y Ecología Sanitarias, en Majadahonda (Madrid), donde se llevaba a cabo el estudio virológico con el aislamiento del virus responsable en cultivos primarios de riñón de mono. La identificación se realizaba mediante sueros antipoliomielíticos preparados por hiperinmunización de conejos y cobayas $^{56}$. Así se comprobó que en 1964 hubo ciento setenta y nueve casos $(0.57$ por cada cien mil habitantes), en 1965 , setenta casos ( 0.22 por cada cien mil habitantes), pasando a trescientos ochenta y ocho en 1966 (0.96 por cada cien mil habitantes), trescientos sesenta y dos en 1967 (1.14 por cada cien mil habitantes) y ciento noventa y uno en 1968 ( 0.58 por cada cien mil habitantes).

En el caso concreto de Valencia, los datos muestran una mejor situación respecto a las cifras nacionales en todos los años estudiados: tres casos en 1964 ( 0.20 por cada cien mil habitantes), dos casos en 1965 (0.13 por cada cien mil habitantes), siete casos en 1966 ( 0.47 casos por cada cien mil habitantes), tres casos en 1967 ( 0.20 casos por cada cien mil habitantes) y seis casos en 1968 ( 0.40 casos por cada cien mil habitantes).

Los autores discuten los motivos por los cuales la enfermedad no había sido eliminada por completo de España pese a la eficacia comprobada de la vacuna tipo Sabin. Su conclusión es que «(...) solo la vacunación precoz, completa y exhaustiva de la población infantil española, sobre todo de los niños que nacen cada año, puede conducir a la desaparición de la enfermedad» ${ }^{57}$.

\section{CONCLUSIONES}

Los estudios epidemiológicos más tempranos sobre la polio en Valencia llevados a cabo por Gómez Ferrer en 1913 y Durich en 1942, demostraron su

56 Valenciano, Mezquita, Pérez Gallardo, Gabriel y Galán (1969), pp. 518-519.

57 Valenciano, MezQuita, PÉRez Gallardo, Gabriel y Galán (1969), p. 562. 
carácter endémico en la zona, con brotes epidémicos periódicos, situación que se mantuvo hasta la introducción de la vacunación antipoliomielítica.

A partir de 1955, la Cátedra de Higiene y Microbiología de la Facultad de Medicina de Valencia fue escenario durante casi una década de una investigación original sobre el virus de la polio, realizada en primer lugar y de una manera incipiente por V. Sanchis-Bayarri Lahoz, formado con Levaditi, uno de los descubridores del virus de la polio, en el Instituto Pasteur y, posteriormente, por V. Sanchis-Bayarri Vaillant. Este último, tras recibir una sólida preparación en virología en diferentes laboratorios de los Estados Unidos y Europa, montó en la mencionada Cátedra un laboratorio de cultivos celulares y desarrolló una técnica diagnóstica propia para el aislamiento del poliovirus. Entre 1959 y 1963 publicó diez trabajos con los resultados de las investigaciones que había llevado a cabo y fue invitado como experto a la V Conferencia sobre Poliomielitis celebrada en Copenhague en 1960. En esos mismos años, F. Pérez Gallardo realizaba investigaciones semejantes en la Sección de Virología y Epidemiología de la Escuela Nacional de Sanidad. La situación periférica de la medicina valenciana de la época y los recursos económicos mucho más escasos de los que disponía en el laboratorio de la Cátedra de Higiene y Microbiología podrían explicar seguramente la menor repercusión de las aportaciones de Sanchis-Bayarri Vaillant.

Por otra parte, los estudios epidemiológicos realizados en Valencia antes y después de la campaña de vacunación oral en 1963 demostraron la eficacia y seguridad de la vacuna de Sabin, al igual que en el resto de España.

Fecha de recepción: 15 de mayo de 2008.

Fecha de aceptación: 20 de noviembre de 2008. 